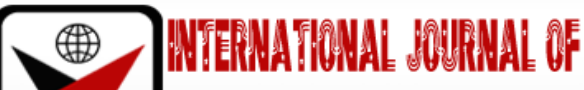

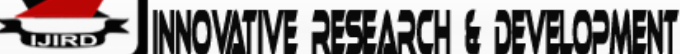

ISSN 2278-0211 (Online)

\section{Effect of Jigsaw Instructional Strategy on Senior School Physics Students' Achievement in Jos, Nigeria}

\begin{tabular}{|c|}
\hline Damoeroem Ejilayomi Omokorede \\
Lecturer, Department of Integrated Science, \\
College of Education Gindiri, Plateau State, Nigeria \\
Dakang Paul. D. \\
Senior Lecturer, Department of Physics, \\
College of Education Gindiri, Plateau State, Nigeria \\
Dapar Lot \\
Lecturer, Department of Physics, \\
College of Education Gindiri, Plateau State, Nigeria \\
\hline
\end{tabular}

\begin{abstract}
:
The poor achievement in science and technology subjects especially physics has brought about major set-back in the sustainable development of the nation. The use of jigsaw instructional strategy in teaching and learning in Nigerian schools could address this problem. This study therefore sought the effect of jigsaw instructional strategy on senior school students' achievement in physics.

The study was a quasi-experimental, pre-test and post-test control group design. Purposive sampling technique was used to select two schools, from which two intact classes of senior secondary school two students in physics took part in the study. A total of 84 students from Jos, Plateau state formed the sample of the study. The instrument used for data collection was Physics Achievement Test (PAT) designed by the researcher with a reliability coefficient of 0.79. Three null hypotheses were formulated and tested using t-test and analysis of variance at 0.05 level of significance. Result of the findings revealed that jigsaw instructional strategy improved students' achievement in physics irrespective of gender and score level. The study recommended that teachers should include the use of jigsaw instructional strategy in the teaching and learning of physics and other subjects at all school level. This could further translate into sustainable development in Nigeria.
\end{abstract}

Keywords: Jigsaw instructional strategy, achievement, physics

\section{Introduction}

The Nigerian educational system has been working towards upgrading her resources to meet up with the level of modernization in developed countries, this includes improvement in science and technology subjects (physics, chemistry, biology and mathematics) at the secondary school level. Science is defined as an activity which results into a testable, falsifiable and veritable body of knowledge (Omosewo, 2009) while technology is the practical application of science; the application of science through technology is crucial for providing the infrastructures that all modern countries need. The goals of education as stated in the National Policy on Education (FRN, 2013, p.2), among others is the development of appropriate skills, mental, physical, social abilities and competencies to empower an individual to live in and contribute positively to the society.

Physics is a branch of science that is concerned with energy and their interaction (Omosewo, 2009); and it is the most basic of the sciences because its concepts and techniques corroborates the progress of all branches of science (Ekee, 2010). Physics is a cross cutting discipline that has been implemented in many sectors of economic advancement which includes health, agriculture, water, energy and information technology. In medicine, x-rays, radioisotope and resonance imaging, are used. In addition, the design of machines and electronics all depend on advances made from the principles of physics. Physics occupies a distinctive position among other science subjects because of the innumerable application of its concepts in improving the environment. For example, the application of simple harmonic motion, in physics can be found in the shock-absorber assembly of a vehicle (damped oscillation), and the supports of a trampoline fabric. The teaching of physics should therefore, exhibit the processes and methods of science, which could enhance sustainable educational and technological development. Many countries are reinforcing and investing in new strategies for the teaching and learning science subjects so as to produce more and better qualified candidates for higher level scientific and technical skills.

Students' low enrolment and poor achievement in physics has been recorded over the years. The West Africa Examination Council (WAEC) Chief examiners' reports (2014 \& 2015) in physics when compared with other science subjects, indicated low enrolment and poor performance of students generally despite the favourable standards of the 
paper and the moderate severity of the marking scheme. Researchers such as Olorukooba (2007) and Gambari (2010) have identified causes of students' poor achievement in physics to include inappropriate instructional strategies, discrimination among students due to ethno-religious crises, abstract nature of physics concepts, lack of qualified teachers, poor infrastructure and inadequate laboratory facilities, non-availability and non-utilization of physics instructional materials.

In Plateau State recently, there has been ethno-religious cliques among people due to the discrimination and lack of unity among ethnic and religious groups. Christians do not move to or live in Muslim dominated areas, Muslims do not send their wards to schools located in Christian dominated areas and vice versa except if the school is located in a strategic position accessible to both religions. Students' especially at the secondary school level also keep to their own cliques in school which may also result to poor achievement in academic subjects and hinder sustainable development in education. The jigsaw instructional strategy was originally designed by Aronson (1978) to help weaken racial cliques in integrated schools; it is a method of structuring classroom activities to make students dependent on each other to learn. Jigsaw is an instructional strategy in which the members of a class are organized into jigsaw (home) groups; the students are then reorganized into expert groups containing one member from each jigsaw group. The members of the expert group work together to learn concepts or solve problems and then return to their jigsaw (home) groups to share their learning. In this way, the work of the expert groups circulates throughout the class, with each person taking responsibility for sharing a piece of the work.

Table 1 and 2 shows a class of 16 students, divided into four groups of four students each. For example, the class is required to study simple harmonic motion ( $\mathrm{SHM}$ ), one group of students learns about the definition and illustration of SHM, another learns about the period, frequency and amplitude of SHM, another learns about the velocity and acceleration of SHM, and so on. The groups are then reconfigured into jigsaw groups and experts take turns teaching their area of expertise to their jigsaw group so that each group learns about every sub-topic.

\begin{tabular}{|c|c|c|c|}
\hline Group One & Group Two & Group Three & Group Four \\
\hline $\begin{array}{c}\text { Definition of SHM, } \\
\text { illustrations (Jummai) }\end{array}$ & $\begin{array}{c}\text { Definition of SHM, } \\
\text { illustrations (Fatima) }\end{array}$ & $\begin{array}{c}\text { Definition of SHM, } \\
\text { illustrations (Kishime) }\end{array}$ & $\begin{array}{c}\text { Definition of SHM, } \\
\text { illustrations (Jim) }\end{array}$ \\
\hline $\begin{array}{c}\text { Period, frequency and } \\
\text { Amplitude (Aladu) }\end{array}$ & $\begin{array}{c}\text { Period, frequency and } \\
\text { Amplitude (Julie) }\end{array}$ & $\begin{array}{c}\text { Period, frequency and } \\
\text { Amplitude (Gaius) }\end{array}$ & $\begin{array}{c}\text { Period, frequency and } \\
\text { Amplitude (Tunde) }\end{array}$ \\
\hline Velocity and & Velocity and & Velocity and & Velocity and \\
Acceleration (Tiwa) & Acceleration (John) & Acceleration (Idris) & Acceleration (Sarah) \\
\hline Energy of SHM (Peter) & Energy of SHM (Peace) & Energy of SHM (Phobe) & Energy of SHM (Sikirat) \\
\hline
\end{tabular}

Table 1: Classification of Students into Home (Jigsaw) Groups with Their Sub-Topics

\begin{tabular}{|c|c|c|c|}
\hline Group One & Group Two & Group Three & Group Four \\
\hline $\begin{array}{l}\text { Definition of SHM, } \\
\text { illustrations (Jummai) }\end{array}$ & $\begin{array}{l}\text { Period, frequency and } \\
\text { Amplitude (Aladu) }\end{array}$ & $\begin{array}{c}\text { Velocity and } \\
\text { Acceleration (Tiwa) }\end{array}$ & $\begin{array}{l}\text { Energy of SHM } \\
\text { (Peter) }\end{array}$ \\
\hline $\begin{array}{c}\text { Definition of SHM, } \\
\text { illustrations (Fatima) }\end{array}$ & $\begin{array}{l}\text { Period, frequency and } \\
\text { Amplitude (Julie) }\end{array}$ & $\begin{array}{c}\text { Velocity and } \\
\text { Acceleration (John) }\end{array}$ & $\begin{array}{c}\text { Energy of SHM } \\
\text { (Peace) }\end{array}$ \\
\hline $\begin{array}{c}\text { Definition of SHM, } \\
\text { illustrations (Kishime) }\end{array}$ & $\begin{array}{l}\text { Period, frequency and } \\
\text { Amplitude (Gaius) }\end{array}$ & $\begin{array}{c}\text { Velocity and } \\
\text { Acceleration (Idris) }\end{array}$ & $\begin{array}{c}\text { Energy of SHM } \\
\text { (Phobe) }\end{array}$ \\
\hline $\begin{array}{l}\text { Definition of SHM, } \\
\text { illustrations (Jim) }\end{array}$ & $\begin{array}{l}\text { Period, frequency and } \\
\text { Amplitude (Tunde) }\end{array}$ & $\begin{array}{c}\text { Velocity and } \\
\text { Acceleration (Sarah) }\end{array}$ & $\begin{array}{l}\text { Energy of SHM } \\
\text { (Sikirat) }\end{array}$ \\
\hline
\end{tabular}

Table 2: Classification of Students into Expert Groups with Their Subtopics

Jigsaw instructional strategy is an effective way for students to become involved in their learning, learn a lot of concepts quickly, share information with other groups, minimize listening time, and be individually responsible for the group's learning, this is because each group need all her members for the whole group to do well. Jigsaw instructional strategy also maximizes interaction and creates an impression of cooperation and respect for other students. Jigsaw groups were formed by the teacher; this is because the group has to be heterogeneous in terms of religion, ethnicity, gender and score level. Students in jigsaw and expert groups sit in their groups with seats arranged in circular or square shape, and each student have duties assigned to them. The duties of each member of the group are summarized;

- Group leader: ensures that every member contributes to group activities and provides appropriate directives among other leadership responsibilities.

- Peace keeper: prevents prolonged argument without reaching a conclusion and conflict between group members.

- Recorder: keeps records of decisions made by the group.

- Time-keeper: monitors the time given for every activity and alert members accordingly, informs the group when the time is up.

- $\quad$ Reporter: reports decision and findings of the group to the class at appropriate time.

- Materials Manager: gathers the material necessary to complete the task. At the end of the task, he/she returns materials and submit the group's work.

The teacher's duty in the jigsaw is to facilitate learning; when students are in expert groups, the teacher support students by helping them to find ways to put information they learnt into their own words, to relate the material to real life conditions, assist students' in solving difficult problems and encourage them to give examples that will help them 
explain the concepts to their groups. Students are encouraged to help each other and to make sure everyone in their group understands the material so that they can be confident in presenting the subtopics to their groups.

\section{Statement of the Problem}

The consistent poor performance of students in physics at the Nigerian senior secondary school certificate examinations leaves one in doubt about the potency of the teaching strategies popularly used by physics teachers in teaching the subject. Investigations into the circumstances that are responsible for the poor academic achievement of students in physics revealed among others, poor motivation, inadequate learning resources, and inappropriate teaching strategies (Oladejo, Olosunde, Ojebisi \& Ishola, 2011; Olanrewaju, 2012; Sofeme \& Amos, 2015). There is very little interaction among the students and between the teacher and students in the use of the traditional (conventional) lecture method, this is because teachers do most of the talking and students contribute less or do not contribute at all in class discussions. The use of talk-and-chalk teaching strategy at the secondary school level usually leads to memorization of facts and concepts. There is need to find out the effectiveness of jigsaw instructional strategy, relative to the conventional lecture method.

\section{Literature Review}

Research findings have showed that students that are exposed to jigsaw instructional strategy showed high levels of self-regard, achieved better in tests, liked school more, reduced truancy, and collaborate successfully with students of other tribes and religions, compared to students exposed to conventional teaching methods (Ali, Hossein \& Mahin, 2012; Mbacho, 2013; Alshammari,2015; Khan, 2016; Abdallah and Filiz, 2017).

Abdallah and Filiz (2017) compared the effects of jigsaw technique and traditional method on laboratory material recognition and usage skills of students in physics; the study was carried out on 63 students that offered general physics lab-1 course at a state University in Turkey. 32 and 31 students were randomly selected from the population and assigned to experimental and control groups respectively. The instruments used for data collection were the material recognition usage skills test, laboratory skills evaluation test and jigsaw opinion scale. Analysis of data was done using $t$-test and it was found that laboratory skills of the experimental group developed more than that of the control group. Jigsaw technique also created a more effective learning environment in laboratory practises.

Khan (2016) investigated the effect of jigsaw cooperative learning on chemistry students' academic achievement in Pakistan. Intact classes from two secondary schools were sampled for the study and students were taught for 45 days. The instrument for data collection was 30 item multiple choice questions and ten short item questions; $t$-test was used for data analysis. Result from the study showed that there was a significant difference between the control and experimental groups in favour of the experimental group.

Alshammari (2015) investigated the effect of jigsaw cooperative learning on academic performance of college students in Saudi Arabia. 40 females whose ages range from 20 to 25 were involved in the study and were divided into two groups: the control group and the experimental group. The experimental group was taught an education course using jigsaw strategy while the control group was taught the same course using the traditional lecture method. Data collection was done using tests and mean, standard deviation and $t$-test were used for data analysis. The results showed that students who were taught using the jigsaw strategy had a better understanding of the content than the students who were taught using traditional lecture method.

Mbacho (2013) investigated the effects of jigsaw cooperative learning strategy on students' achievement in senior school mathematics in Laikipia East district, Kenya. Four groups were involved in the study, the two experimental groups received the jigsaw cooperative learning Strategy as treatment and two control groups were taught using the conventional teaching methods. 160 students were randomly selected from Laikipia East district and mathematics achievement test (MAT) was used for data collection. Data was analysed using $t$-test. Findings from the study showed that learners taught using jigsaw cooperative learning strategy performed better than those taught using conventional teaching method. The results also show that there was no significant difference in achievement of students based on gender when they were taught using jigsaw cooperative learning strategy.

Ali, Hossein and Mahin (2012) investigated and compared the effect of jigsaw cooperative learning on the academic achievement of 2nd-grade middle school student in Bandar Abbas city. 153 students were involved in the study and the instrument used was students' academic achievement test. Analysis of data was done using ANCOVA. The findings of the study indicated that the jigsaw cooperative learning method has significant effect on students' academic achievement. The instructional values of the jigsaw instructional strategy have been established; however, there are more research works on jigsaw instructional strategy in countries outside Nigeria. Also, the extent of the effect of the jigsaw instructional strategy on Nigerian senior secondary school students' achievement in physics is yet to be fully explored. In addition, it was observed that many of the studies were focused mostly on subjects like biology and mathematics. Based on these facts, the present study examined the effects of the jigsaw instructional strategy on senior secondary school students' attitude, achievement and retention in physics in Jos metropolis, Plateau State.

\section{Research Questions}

- What is the difference between the mean achievement scores among students that learn physics using jigsaw instructional strategy and those that learn using conventional method?

- Is there any difference between the mean achievement scores among students that learn physics using jigsaw instructional strategy based on gender? 
- Is there any difference between the mean achievement scores among students that learn physics using jigsaw instructional strategy based on score level?

\section{Research Hypotheses}

To achieve the objectives earlier stated, the following null hypotheses were formulated and tested at 0.05 level of significance.

- $\mathrm{HO}_{1}$ : There is no significant difference in the mean achievement scores among students that learn physics using jigsaw instructional strategy and those that learnt physics with conventional method.

- $\mathrm{HO}_{2}$ : There is no significant difference in the mean achievement scores among students that learn physics using jigsaw instructional strategy based on gender.

- $\mathrm{HO}_{3}$ : There is no significant difference in the mean achievement scores among students that learn physics using jigsaw instructional strategy based on score level.

\section{Methodology}

This study adopted the quasi-experimental research, of the pre-test, post-test control group. The area of study was Jos metropolis which constitutes parts of Jos south and Jos north local government areas of Plateau State, Nigeria. The population comprised of 84 senior secondary school two students offering physics from two purposively selected schools. Students from two intact classes (one from each participating schools) were involved in the study, with 43 and 41students in the experimental and control groups respectively. Students in the experimental group were classified into three score levels (high, medium, low) based on the results obtained from their senior school one (SS1) third term continuous assessment in physics. Students whose scores fell between 70-100percent were classified as high scorers; students whose scores fell between 50-69percent were classified as medium scorers while students whose scores fell between 049 percent were classified as low scorers.

Two research instruments were used to obtain data for this study. The researcher-designed Instructional Plans (IP) on the concept of simple harmonic motion for experimental and control groups (EG and CG), and Physics Achievement Test (PAT). IP was used to instruct experimental group and to teach control group the selected physics concept; simple harmonic motion. The PAT test item was made up of 20 multiple-choice questions and four theory questions. PAT was validated by three university lecturers from the faculty of science education and two senior secondary school physics teachers. Their comments were used to modify PAT. The modified PAT was tested and a reliability co-efficient of 0.79 was obtained using Kuder-Richardson's formula 21. Mean and standard deviation were used to answer the research questions while the hypotheses were tested using $t$-test and Analysis of Covariance (ANCOVA). The Statistical Package for Social Sciences (SPSS 22.0) software was used as a platform for the data analysis.

\section{Procedure for Data Collection}

Letters of introduction and consent forms were given to the school authorities and the physics teachers to seek permission to use the school's classrooms and engage the students for this study. The researcher sought the consent of the physics teachers to act as research assistants for this study. The two physics teachers from the participating schools gave their consent. The researcher also sought the consent of the students by giving them consent form to read and indicate their willingness to participate in the experiment. The researcher made it clear to the participating groups that their efforts, contributions and scores will be kept confidential and only for this study. The researcher took into consideration the school's lesson periods in order not to disrupt the school programs. Students from the two participating schools learnt the selected physics contents as prepared by the researcher during the same week, so as to obtain reliable data for the study. The experiment lasted for eight weeks.

\section{Results}

- Research Question 1: What is the difference between the mean achievement scores among students that learn physics using jigsaw instructional strategy and those that learn using conventional method?

\begin{tabular}{|c|c|c|c|c|c|c|}
\hline & & \multicolumn{2}{|c|}{ Pre-test } & \multicolumn{2}{c|}{ Post-test } & Mean Gain \\
\cline { 3 - 6 } Groups & $\mathbf{N}$ & $\mathrm{M}$ & $\mathrm{SD}$ & $\mathrm{M}$ & $\mathrm{SD}$ & Scores \\
\hline Control & 41 & 7.32 & 1.84 & 23.37 & 4.32 & 16.05 \\
\hline Experimental & 43 & 6.37 & 1.90 & 33.81 & 3.25 & 27.44 \\
\hline
\end{tabular}

Table 3: Mean achievement scores of students in the experimental and control groups

Table 3 showed the mean gain scores of students that participated in the physics achievement test. The mean gain scores of students that learnt physics with jigsaw instructional strategy and conventional method were 27.44 and 16.05 respectively. This means that students achieved better when they learn physics using jigsaw instructional strategy than their counterparts in the control group. However, there was an increase in their achievement, where the experimental group had a mean gain score of 27.44 while the control group had a mean gain score of 16.05 .

- Hypothesis 1: There is no significant difference in the mean achievement scores among students that learn physics using jigsaw instructional strategy and those that learnt physics with conventional method. 


\begin{tabular}{|c|c|c|c|c|c|c|c|}
\hline Group & $\mathbf{N}$ & $\mathbf{M}$ & SD & $\mathbf{t}$ & $\mathbf{d f}$ & $\begin{array}{c}\text { Sig } \\
\text { (2 tailed) }\end{array}$ & Decision \\
\hline Experimental & 43 & 33.81 & 3.25 & -12.6 & 82 & 0.01 & $\mathrm{~S}$ \\
\hline Control & 41 & 23.37 & 4.32 & & & & \\
\hline & & & & & & & $p<0.05$ \\
\hline
\end{tabular}

Table 4: t-test Analysis of Mean Achievement Scores of Students in the Experimental and Control Groups

Table 4 showed the analysis of the achievement scores of students in control and experimental groups. The calculated $t$-value of -12.6 was computed with a degree of freedom $(1,82)$ at 0.05 critical levels. Since $p$-value of 0.00 was less than the alpha value, hypothesis one was rejected. This means that a significant difference existed in the achievement scores of students in experimental $(M=33.81, S D=3.25)$ and control $(M=23.37, S D=4.32)$ groups. This implies that students that learn physics using jigsaw instructional strategy achieved better than their counterparts in the control group $(t(82)=-12.6 ; p<0.05)$.

- $\quad$ Research Question 2: Is there any difference between the mean achievement scores among students that learn physics using jigsaw instructional strategy based on gender?

\begin{tabular}{|c|c|c|c|c|c|c|}
\hline \multirow{2}{*}{ Gender } & \multirow{2}{*}{$\mathbf{N}$} & \multicolumn{2}{|c|}{ Pre-test } & \multicolumn{2}{c|}{ Post-test } & \multirow{2}{*}{$\begin{array}{c}\text { Mean Gain } \\
\text { Scores }\end{array}$} \\
\cline { 3 - 6 } & & M & SD & M & SD & 27.41 \\
\hline Male & 22 & 6.41 & 2.04 & 33.82 & 3.43 & 27.48 \\
\hline Female & 21 & 6.33 & 1.80 & 33.81 & 3.14 & \\
\hline
\end{tabular}

Table 5: Mean Achievement Scores of Students in the Experimental Group Based on Gender

Table 5 revealed the mean gain scores of male and female students that learn physics using jigsaw instructional strategy. The difference in the mean gain scores of male $(M=27.41)$ and female $(M=27.48)$ students was 0.07 which is negligible.

- Hypothesis 2: There is no significant difference in the mean achievement scores among students that learn physics using jigsaw instructional strategy based on gender.

\begin{tabular}{|c|c|c|c|c|c|c|c|}
\hline Gender & $\mathbf{N}$ & $\mathbf{M}$ & SD & $\mathbf{t}$ & $\mathbf{D f}$ & $\begin{array}{c}\text { Sig } \\
\text { (2 tailed) }\end{array}$ & Decision \\
\hline Male & 22 & 33.82 & 3.43 & 0.01 & 42 & 0.99 & NS \\
\hline Female & 21 & 33.81 & 3.14 & & & & $p>0.05$ \\
\hline
\end{tabular}

Table 6: t-test Analysis of Mean Achievement Scores of Students in Experimental Group Based on Gender

The analysis on Table 6, revealed the achievement scores of male and female students in the experimental group. The calculated $t$-value of 0.09 with degree of freedom $(1,42)$ was computed at 0.05 critical levels. Since the calculated significance 0.99 is greater than the critical significance 0.05 , hypothesis two was not rejected. This suggests that there was no significant difference in the post-test achievement scores of males $(M=33.82, S D=3.43)$ and female $(M=33.81, S D$ $=3.14)$ students that learn physics using jigsaw instructional strategy $(t(42)=0.09 ; p>0.05)$.

- Research Question 3: Is there any difference between the mean achievement scores among students that learn physics using jigsaw instructional strategy based on score level?

\begin{tabular}{|c|c|c|c|c|c|c|}
\hline \multirow{2}{*}{ Groups } & \multirow{2}{*}{$\mathbf{N}$} & \multicolumn{2}{|c|}{ Pre-test } & \multicolumn{2}{c|}{ Post-test } & \multirow{2}{*}{$\begin{array}{c}\text { Mean Gain } \\
\text { Scores }\end{array}$} \\
\hline High & $\mathrm{M}$ & $\mathrm{SD}$ & $\mathrm{M}$ & $\mathrm{SD}$ & 27.90 \\
\hline Medium & 10 & 7.60 & 1.84 & 35.50 & 3.60 & 27.33 \\
\hline Low & 21 & 6.38 & 1.40 & 33.71 & 2.81 & 27.25 \\
\hline
\end{tabular}

Table 7: Mean Achievement Scores of Students in the Experimental Group based on Score Level

Table 7 revealed the mean gain scores of high, medium and low scoring students that learnt physics using jigsaw instructional strategy. The mean gain score of high, medium and low scoring students were 27.90, 27.33 and 27.25 respectively. High scoring students had the highest mean gain score, followed by the medium and low scoring students respectively. JIS was effective in enhancing student's achievement.

- Hypothesis 3: There is no significant difference in the mean achievement scores among students that learn physics using jigsaw instructional strategy based on score level. 


\begin{tabular}{|c|c|c|c|c|c|c|}
\hline Source & $\begin{array}{c}\text { Type III Sum } \\
\text { of Squares }\end{array}$ & $\boldsymbol{d f}$ & $\begin{array}{c}\text { Mean } \\
\text { Square }\end{array}$ & $\boldsymbol{F}$ & Sig. & $\begin{array}{c}\text { Partial Eta } \\
\text { Squared }\end{array}$ \\
\hline Corrected Model & $60.33^{\mathrm{a}}$ & 3 & 20.11 & 2.04 & 0.12 & 0.14 \\
\hline Intercept & 2811.13 & 1 & 2811.13 & 285.37 & 0.00 & 0.88 \\
\hline Pretest & 13.52 & 1 & 13.52 & 1.37 & 0.25 & 0.03 \\
\hline Score level & 21.36 & 2 & 10.68 & 1.08 & 0.35 & 0.05 \\
\hline Error & 384.18 & 39 & 9.85 & & & \\
\hline Total & 49610.00 & 43 & & & & \\
\hline
\end{tabular}

Table 8: One-Way ANCOVA Analysis of the Mean Achievement Scores of Students in the

Experimental Group Based on Score Level

$$
P>0.05
$$

Table 8 showed the one-way between groups analysis of covariance conducted to find the influence of score level on students' achievement when they learn physics using jigsaw instructional strategy (JIS). Students' pre-test scores were used as the covariate in the analysis. There was no significant difference in the mean achievement scores of students that learn physics using JIS based on score level, $F(2,39)=1.08, p=0.35$; the null hypothesis 3 is therefore not rejected. This means that high $(M=35.50, S D=3.60)$, medium $(M=33.71, S D=2.81)$ and low $(M=32.58, S D=3.34)$ scorers had similar achievement scores when they learn physics with jigsaw instructional strategy.

\section{Discussion of Findings}

The findings of this study showed that the use of jigsaw instructional strategy improved students' academic achievement in physics. This implies that jigsaw instructional strategy can be used in improving students' academic achievement in physics. This is in agreement with the findings of Ali, Hossein and Mahin (2012); Mbacho (2013); Alshammari (2015); Khan (2016); and Abdallah and Filiz (2017) that had worked on the effect of jigsaw instructional strategy on students' academic achievement in physics and other science subjects and found the strategy to be effective in improving students' academic achievement. The study further revealed that jigsaw instructional strategy improved students' achievement in physics irrespective of gender and score level. This is in line with the position of Gambari (2010) that there was no significant difference in the achievement of male and female students when exposed jigsaw instructional strategy in physics. Abdulwahab, Oyelekan and Olorundare (2016) also reported that low, medium and high scorers had improved academic achievement after students were exposed to active instructional strategy.

\section{Conclusion}

The study concluded that students that learnt physics using Jigsaw instructional strategy (JIS) had improved achievement than those in the control group. The study also concluded that gender did not have influence on the achievement of students that learnt physics using JIS. Score levels did not also have influence on the achievement of students that learnt physics using JIS. It can therefore be concluded from the study that JIS could be used to guide low, medium and high scoring students in the teaching and learning of physics.

\section{Recommendations}

The following recommendations were made;

- Physics teachers' emphasis should shift from teacher-centred approach of teaching to active learning strategies such as jigsaw instructional strategy. Jigsaw instructional strategy should be used to improve students' achievement in physics.

- Students of different score levels and gender should be encouraged to use jigsaw instructional strategy for effective learning; jigsaw groups should consist of high, medium and low scoring students so that they can help each other to learn.

- Curriculum planners and developers should include jigsaw instructional strategy in the curriculum for the teaching and learning of physics concepts in senior secondary schools.

\section{References}

i. Abdallah, A. \& Filiz, B. (2017). The effects of jigsaw technique on the students' laboratory material recognition and usage skills in general physics laboratory-1 course. Universal Journal of Educational Research 5(7), 10731082.

ii. Abdulwahab, N., Oyelekan, O. S., \& Olorundare, A. S. (2016). Effects of cooperative instructional strategy on senior secondary students' achievement in electrochemistry. Eurasian Journal of Physics \&Chemistry Education, $8(2), 37-48$.

iii. Ali, A. S., Hossein, Z., \& Mahin, J. (2012) An investigation into the effect of cooperative learning with focus on jigsaw technique on the academic achievement of $2^{\text {nd }}$ grade middle school students. Journal of Life Science and Biomedicine, 2(2), 21 - 24.

iv. Alshammari, N. M. (2015). Effects of cooperative learning on academic performance of college students in Saudi Arabia. Unpublished M.Ed. Dissertation, University of New York, Fredonia, New York.

v. Aronson, E. (1978). The Jigsaw Classroom. Beverly Hills, USA: Sage Publications. 
vi. Aronson, E. (2008). The Jigsaw Classroom. Social Psychology Network. Retrieved from http://www.jigsaw.org/Hsteps.

vii. Ekee, P. (2010). The importance of physics to man and society. Retrieved from http://impotanceofphysics.blogspot.com.ng/2010/06/importance-of-physics.html?m=1.

viii. Federal Republic of Nigeria. (2013). National Policy on Education (6 $\left.6^{\text {th }} \mathrm{ed}\right)$. Lagos, Nigeria: NERDC Press.

ix. Gambari, I. A. (2010). Effect of computer-supported cooperative learning strategies on the performance of senior secondary students in physics, in Minna, Nigeria. Unpublished Ph. D Dissertation, University of Ilorin, Nigeria.

x. Khan, G. N. (2016). Effect of jigsaw technique of cooperative learning on academic achievement of secondary school students. Global Advancement Research Journal of Education Research and Review, 5(2), 028-031. Retrieved from http://ganj.org/garjerr/index.htm

xi. Mbacho, N. W. (2013). Effects of jigsaw cooperative learning strategy on students' achievement in secondary school mathematics in Laikipia east district, Kenya. Unpublished M.Ed. Dissertation, Egerton University, Kenya.

xii. Odagboyi, I. A., Otuka, J. O. E., \& Uzoehi, B. C. (2014). Efficacy of the jigsaw cooperative learning approach in enhancing biology students' achievement and conceptual change. Retrieved from http://www.stanconference.com/uploads/2014/19

xiii. Oladejo, M. A., Olosunde, G. R., Ojebisi, A. O., \& Ishola, O. M. (2011). Instructional materials and students' academic achievement in physics: Some policy implications. European Journal of Humanities and Social Sciences, 2(1), 112-126.

xiv. Olanrewaju, R. R. (2012). Effects of cooperative learning strategy with models on academic achievement and retention of biology concepts among pre national students in Kaduna. Unpublished Ph. D Dissertation, Ahmadu Bello University, Zaria.

xv. Olorukooba, S. B. (2007). The relative effect of cooperative instructional strategy on the academic achievement of senior secondary school students in chemistry. Journal of Educational Research and Development, 1(2), 1 - 5.

xvi. Omosewo, E. O. (2009). Views of Physics teachers on the need to train and retrain Physics teachers in Nigeria. International Multi-Disciplinary Journal, 3(1), 313-324.

xvii. Sofeme, R. J. \& Amos, Z. H. (2015). Students' attitude towards science subjects in senior secondary schools in Adamawa state, Nigeria. International Journal of Research in Applied, Natural and Social Sciences, 3(3), $117-124$.

xviii. WAEC (2014). Chief examiners' report, International Journal, Lagos: Waec Publishers.

xix. WAEC (2015). Chief examiners' report, International Journal, Lagos: Waec Publishers. 